\title{
Vegetation Database of Central New Mexico - desert grass- and shrubland net-primary production quadrat data
}

\author{
Esteban Muldavin \& John Mulhouse
}

\begin{abstract}
The Vegetation Database of Central New Mexico (GIVD ID NA-US-011) is part of a long-term study to monitor net primary production across three distinct ecosystems in central New Mexico, United States: creosote dominant shrubland, black grama dominant grassland, and blue grama dominant grassland. Since 1999, sampling of permanent 1m x 1m plots has been performed twice per year (spring/autumn) within black grama grassland and three times per year (spring/autumn/winter) within creosote shrubland. Since 2002, sampling has also been performed twice per year (spring/autumn) within blue grama grassland. This sampling of 120 plots (40 per ecosystem) remains ongoing at the Sevilleta National Wildlife Refuge, Socorro County, New Mexico. Species are later harvested from adjacent areas to determine biomass and results have documented vegetation dynamics within and between these ecosystems.
\end{abstract}

Keywords: black grama; blue grama; creosote; Chihuahuan Desert; Sevilleta; United States.

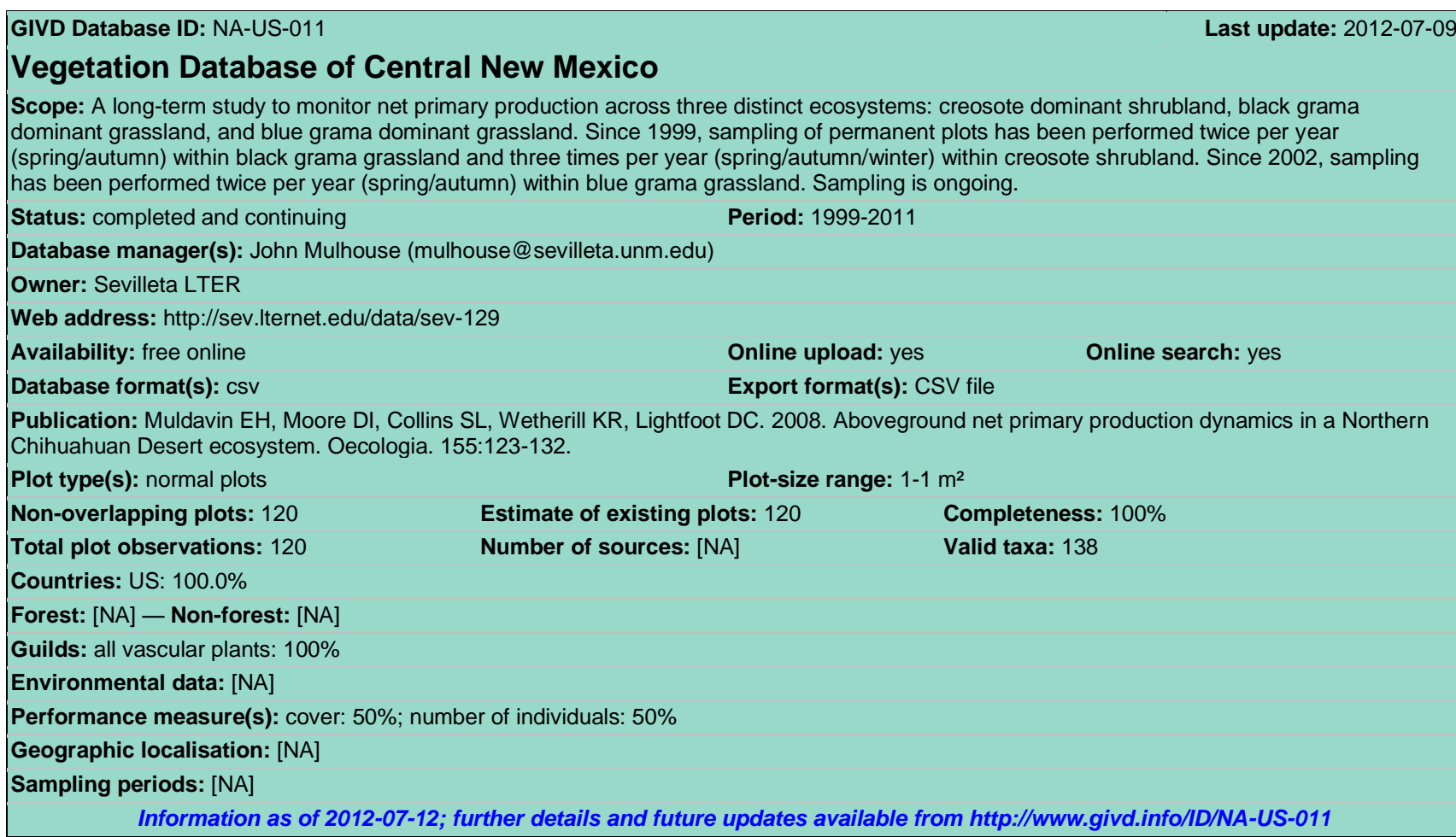

Esteban Muldavin (muldavin@unm.edu), John Mulhouse*(mulhouse@ sevilleta.unm.edu)

Department of Biology, University of New Mexico, MSC03 2020, 87131 Albuquerque, UNITED STATES

*Corresponding author 